\title{
FEMORAL GROWTH AFTER OCCLUSION OF THE PRINCIPAL NUTRIENT CANAL IN DAY-OLD RABBITS
}

\author{
M. Brookes, Liverpool, ENGLAND \\ From the Department of Anatomy, University of Liverpool
}

Study of the blood supply of bone has as one of its objectives a determination of the relative value of three possible sources of arterial blood to long bones, namely: the periosteal network; the principal nutrient artery; and the small arteries entering the ends of the bones. Since the work of Ollier (1867) on the importance of the periosteum in bone regeneration periosteal arteries entering cortical bone were described (Langer 1876, Testut 1880, Lexer 1922 and Kolodny 1923). Doubt has been thrown on this proposition by Moore and Corbett (1914) who said that the periosteal circulation was of no value in the healing of fractures. In his famous paper (1927) Johnson said that periosteal bone was well and surely laid down only upon a foundation of old bone. He also asserted that there was no bleeding from bone defects after the nutrient and metaphysial blood supplies had been cut off. Drinker, Drinker and Lund (1922), after injection experiments, considered the periosteal circulation of no importance for their subsequent perfusion studies. Brunschwig (1930) was unable to produce any infarction of the tibia after stripping the entire shaft of its periosteum in fifteen adult dogs; and Wu and Miltner (1937) recorded bone lengthening after a similar procedure in young rabbits. Marneffe (1951) stated that only the outer third of rabbit bone cortex is dependent on a periosteal blood supply. Recently the very existence of periosteal arteries in rabbit cortical bone has been denied by Brookes and Harrison (1957) who, from their radiological studies, envisaged a copious venous drainage route in the microscopic vascular channels passing centrifugally from the cortex out into the periosteal capillary bed.

It is accepted here that a periosteal arterial supply in the rabbit is a negligible factor in the vascularisation of long bones. In view of the importance attributed by anatomists and surgeons to the role of the principal nutrient artery in bone nutrition it is wise to make a functional comparison of this artery against the small arteries that enter the extremities of the long bones (Hunter 1743). An attempt has been made in this paper to gain this by obliterating the principal nutrient canal of the femur in day-old rabbits so that it is dependent solely upon its epiphysial and metaphysial arteries for a supply of blood, and observing the subsequent growth of the bone.

\section{MATERIALS AND METHODS}

Day-old rabbits were anaesthetised with open ether, and an incision was made on the medial side of the thigh from the inguinal groove to just above the medial femoral condyle. With blunt dissection the femoral bundle and lateral circumflex femoral artery were revealed. Arising from the root of this, the principal nutrient artery was readily followed in the interval between the vastus medialis and adductor group of muscles distally to its entry into the principal nutrient canal of the femur, situated just below the lesser trochanter.

Although it is a simple matter to ligate the nutrient artery alone, leaving the vein intact, it was felt that permanent occlusion of the canal was the procedure of choice because of the possibility of regeneration of the ligated nutrient artery into a patent canal. The consequent disturbance of the venous side of the circulation in the femur would be negligible in view of the profuse venous drainage at the bone extremities (Langer 1876, Harrison and Gossman 1955) and at the surface of the diaphysis (Brookes and Harrison 1957).

vol. 39 B, No. 3, AUGUST 1957 
The technique of occlusion was based on the work of Nakahara and Dilger (1909) on heterotopic bone formation. The periosteum and diaphysial surface in the immediate neighbourhood of the canal were curetted and the scrapings packed into it, the nutrient bundle being destroyed in the process. The operation field was closed by three blanket sutures, the incision painted with proflavine solution, and the rabbit returned to the nest after it had recovered from the anaesthetic. Subsequent bone production by the displaced periosteal fragments brought about complete bony occlusion of the canal, as judged by inspection of the cleaned adult femora at necropsy.

The rabbits were in four separate litters. Occlusion of the nutrient canal vas carried out on right or left femur or both femora, each litter retaining its own controls. After the initial mortality among the young, the four litters yielded three, six, six and eight animals respectively, the growth of whose femora could be followed for five months until they reached maturity.

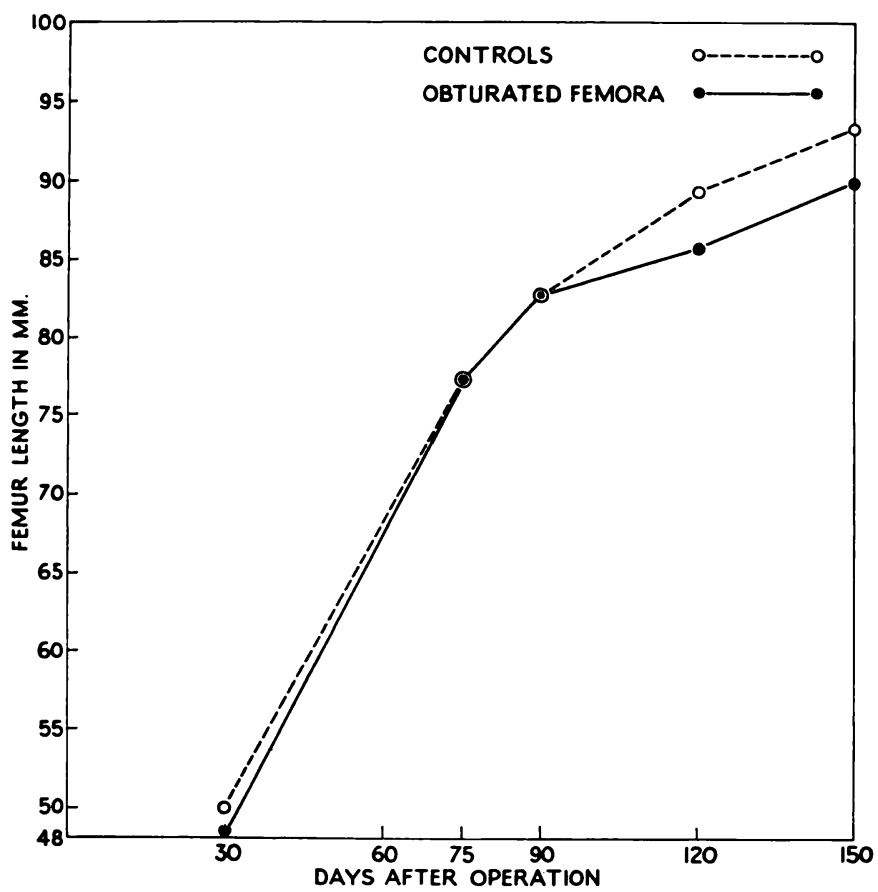

FIG. 1

Growth curves of rabbit femora.

Femur length was measured indirectly at $30,75,90,120$ and 150 days after the operation. From radiographs of the hind limbs applied as closely as possible to the film, the greatest distance was measured with calipers between the femoral head and the mid-point of a line joining the distal surfaces of the condyles. A radiographic method for measuring bone growth in goats was used by Bisgard (1936) whose results imply an accuracy sufficient to detect differences of 0.5 millimetre.

One hundred and fifty days after operation the animals were killed by intravenous nembutal, and the arteries of the hind limbs were injected with a barium sulphate suspension (" Micropaque," Damancy and Co.) through the abdominal aorta. After fixation in 5 per cent formol-saline the femora were cleaned of all extra-osseous tissue and their greatest length measured directly with calipers.

The cleaned femora were placed in a 5 per cent solution of nitric acid in 5 per cent formol-saline. The decalcified specimens so obtained were radiographed on Kodaline film so that the intra-osseous arteries of the bones operated upon and control bones could be visualised. 


\section{RESULTS}

The direct and indirect measurements of femur length at stated intervals during the growing period are set out in Table I. The effect of occlusion of the nutrient canal on femoral growth was calculated for each period from the data in the columns by means of the analysis

TABLE I

Femur Length in Millimetres, Rabit Data

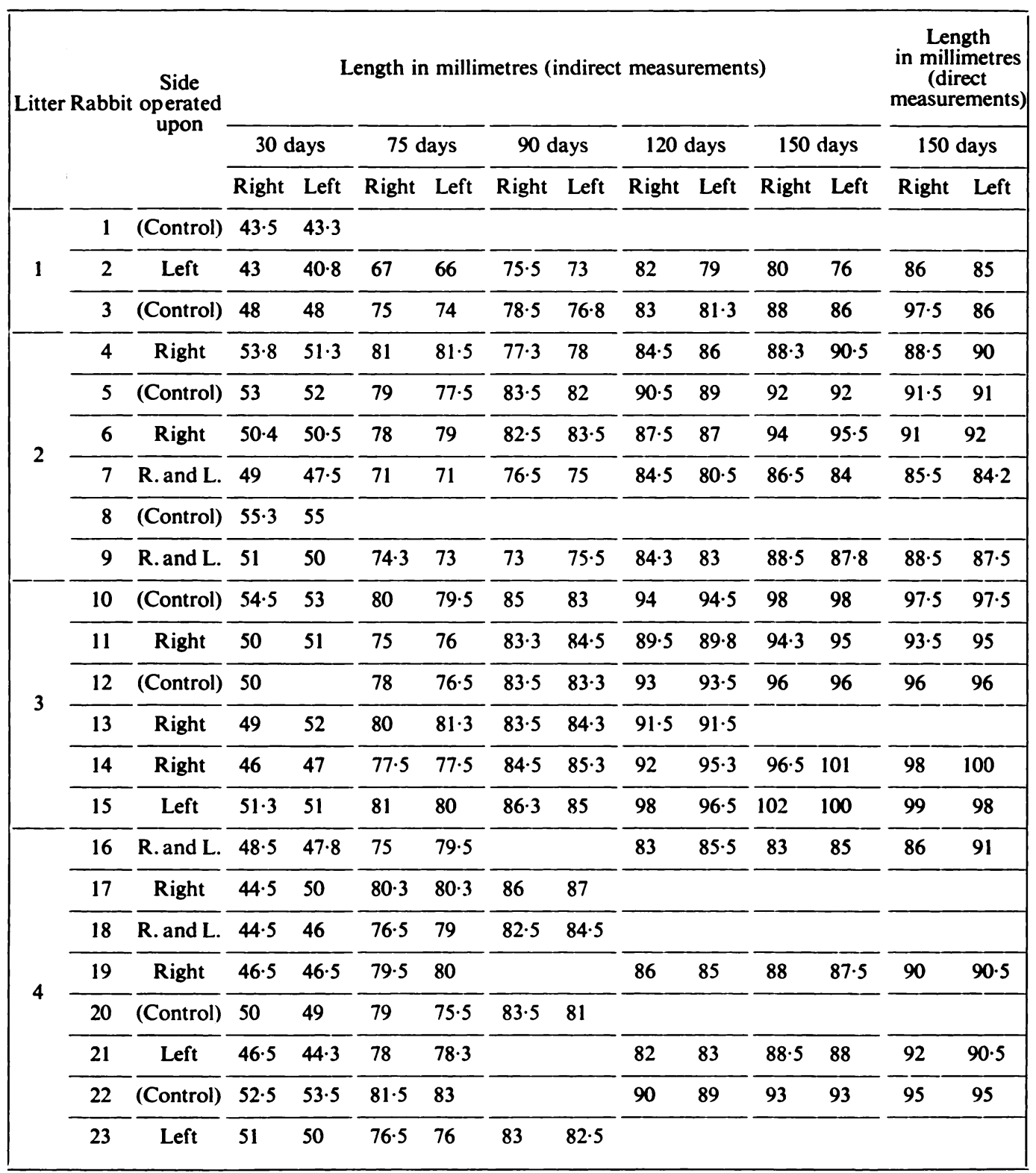

of variance, including the operation of occlusion and leg-side as sources of variation. Figure 1 shows that the femur of a newborn rabbit deprived of its principal nutrient artery has an almost normal growth curve. A significant deficiency in length of the order of 3 per cent only vol. 39 B, No. 3, AUGUST 1957 
occurs during the initial and final phases of growth, while in the intermediate phase of seventyfive to ninety days there is no significant difference in length between occluded and control femora.

To test the validity of the indirect measurements from radiographs, the direct and indirect data for right and left femora at the close of the experiment at 150 days were compared by means of Student's " $t$ " test. The comparison yielded $t=0.3$ and $0.43(P=0.8$ and 0.7$)$ for the right and left sides respectively, showing that the radiographic data have the same value in a large group of observations as direct measurements of the cleaned bones. The mean

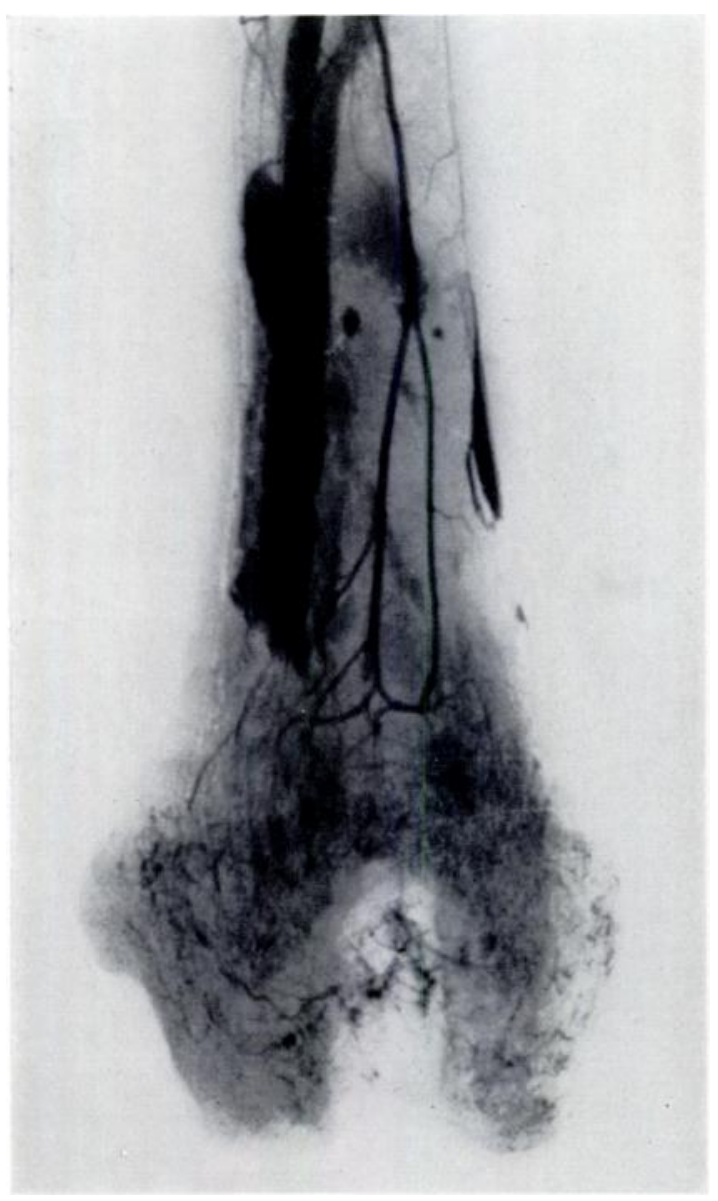

FIG. 2

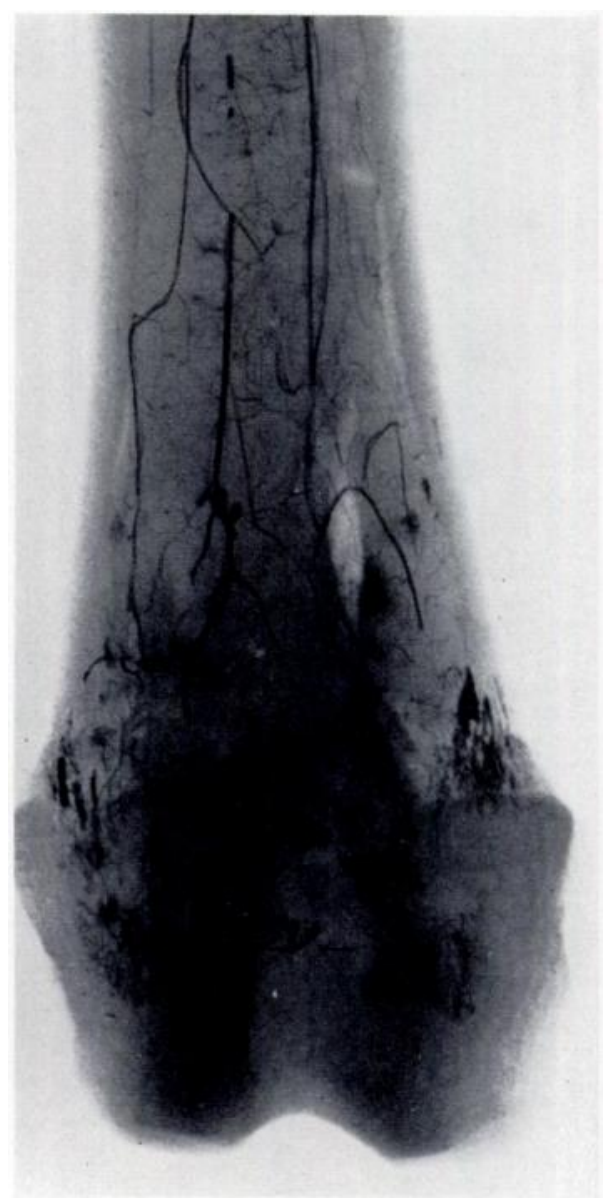

FIG. 3

Figure 2-Arteriograph of the distal part of a rabbit femur 150 days after occlusion of the principal nutrient canal, showing intra-osseous metaphysial anastomoses. $(\times 3 \cdot 5$.$) Figure 3$-Arteriograph of the distal part of a normal rabbit femur. $(\times 3 \cdot 5$.)

deficiency in length as calculated from direct measurements at 150 days is 77 per cent of that obtained from an analysis of indirect data at the same period (Table II). Because indirect measurements seem to magnify the length differences when present, all mean differences calculated from indirect data have been reduced in this ratio before the percentage diminution in length at the various time intervals has been determined and the growth curves for control and occluded femora have been constructed.

Radiological examination of the injected bones shows that the medullary arteries of occluded specimens are well filled and that the general vascular pattern is but little disturbed. 
Filling has taken place through epiphysial and metaphysial arteries which have undergone enlargement. Above the condyles conspicuous intra-osseous anastomoses are seen which are not normally present (Figs. 2 and 3), and the artery of the trochanteric fossa at the proximal end of the femur has greatly enlarged and become an important supply channel to the medullary arterial system (Figs. 4 and 5).

\section{DISCUSSION}

Occlusion of the nutrient canal eliminates the functional activity of the nutrient vein and sympathetic nerve fibres from the growing femur besides that of the principal nutrient artery. The effects of removal of the nutrient vein may be discounted for the reasons already given, and interruption of an automatic pathway to the bone may be taken as of no effect because all experimental investigations of lumbar sympathectomy and ganglionectomy on bone growth in animals have had negative results (Bisgard 1931, 1933, Wilson and Thompson 1939).

TABLE II

Diminution in Length of the Adult Rabbit Femur after Occlusion of the Principal Nutrient Canal in the Newborn

\begin{tabular}{|ccccc|}
\hline $\begin{array}{l}\text { Days after } \\
\text { operation }\end{array}$ & $\begin{array}{c}\text { Diminution in } \\
\text { length } \\
\text { (millimetres) }\end{array}$ & $\begin{array}{c}\text { Corrected } \\
\text { diminution } \\
\text { (millimetres) }\end{array}$ & $\begin{array}{c}\text { Mean femur length } \\
\text { (controls) } \\
\text { (millimetres) }\end{array}$ & $\begin{array}{c}\text { Percentage } \\
\text { diminution }\end{array}$ \\
\hline 30 & $2 \cdot 1$ & 1.6 & 50.0 & $3 \cdot 1$ \\
\hline 75 & 0 & 0 & 77.2 & nil \\
\hline 90 & 0 & 0 & 82.6 & nil \\
\hline 120 & 4.6 & 3.5 & 89.2 & 3.9 \\
\hline 150 & 4.4 & 3.4 & 92.8 & 3.7 \\
\hline 150 & (Dircct measurement) & (Direct measurement) & (Direct measurement) \\
\hline
\end{tabular}

A fundamental factor in osteogenesis is an adequate blood supply. Variations in nutrition of the growth cartilage will cause shortening or lengthening of long bones-for example the hypertrophy of limb bones associated with arterio-venous aneurysms (Horton 1932, Chandler 1937). Ferguson (1933) first stated that interruption of the medullary arteries and diversion of blood to the growth cartilages accounted for the increased growth rate observable in long bones affected by a variety of pathological conditions, such as fractures, chronic infections and tumours. Occlusion of the nutrient canal may result in diversion of blood into the epiphysial and metaphysial arteries, with possible ischaemia of the diaphysis. Kistler (1934), who blocked many arterioles with large carbon particles, produced some fibrosis of the central marrow. Huggins and Wiege (1939), who avulsed the principal nutrient artery and vein, found only a temporary anaemia of bone marrow, which after seventy days was histologically normal. It is probable that, while a collateral circulation is developing in the bone extremities, there is a diminution in the femoral blood supply and to the growth cartilages, thus accounting for the growth lag of the occluded femora in the first thirty days.

With the establishment of a collateral circulation by means of the anastomoses between the metaphysial arteries and the principal nutrient artery (Figs. 2 and 4 ) the blood flow near the growth cartilages is increased, bringing about equalisation in length of occluded and normal femora in the intermediate growth phase. In the final phase, 120 to 150 days, there appears to be a relative decrease in the nutrition of the growth cartilages to account for the 3.7 per cent retardation in femoral growth at maturity. The reason for this is not clear. It seems probable that towards the end of growth the collateral circulation is not quite able

vol. 39 B, No. 3, AUGUST 1957 
to furnish the same quantity of blood to the medullary arterial system as when a nutrient artery is also available as a supply channel. Nevertheless, the collateral circulation in metaphysial intra-osseous anastomoses is 96 per cent functionally adequate; consequently the dictum of Harris (1929) that diaphysial terminal arteries are end-arteries cannot be accepted.

The medullary arterial system, fed by nutrient, metaphysial and epiphysial arteries, is to be regarded as the vascular mechanism for the delivery of blood to long bones. In the rabbit

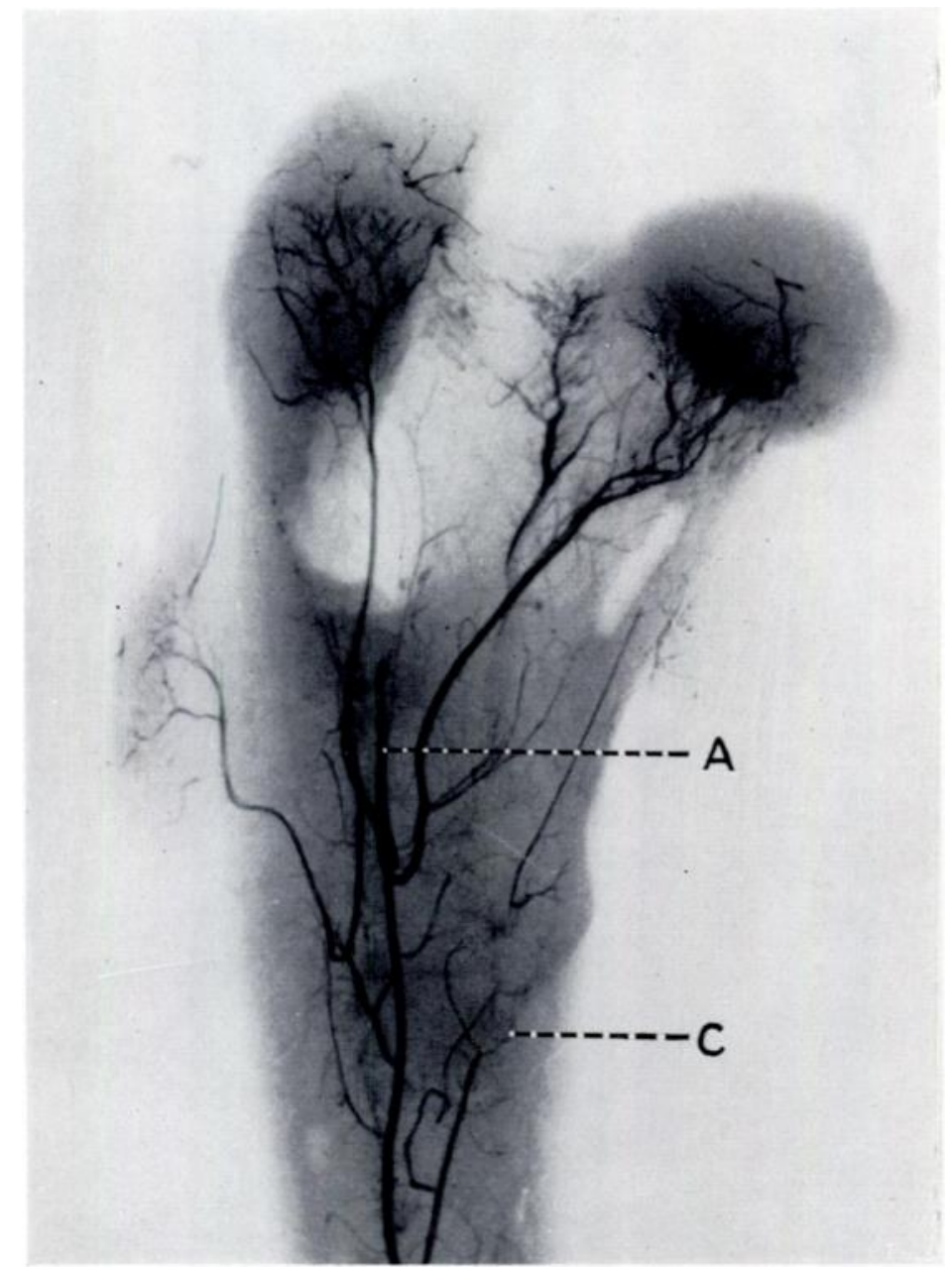

FIG. 4

Arteriograph of the upper part of a mature rabbit femur. The principal nutrient canal, whose site is indicated at $C$, was occluded 150 days previously, twenty-four hours after birth. The artery of the trochanteric fossa, A, has taken over the blood supply of the upper end of the femur and become a main supply channel to the medullary arterial system. $(\times 4$.)

the principal nutrient artery is not of vital importance because the medullary arterial system can rapidly accommodate itself to dependence on the metaphysial arteries alone.

These results may be compared with the evidence for bone lengthening after fractures in children, in whom presumably the same local vascular mechanism is active that determined the growth curve of the occluded femora. Many authors have reported this occurrence (Truesdell 1921, Burdick and Siris 1923, David 1924, Chandler 1937). Although decrease in 
shortening, or occasional actual lengthening of an affected long bone has been described, the patients have been kept under observation for a comparatively short time, usually less than two years after fracture, and offered data generally fall within the ages four to fourteen years. The clinical evidence supports the finding of stimulation of osteogenesis in the intermediate growth phase. Since epiphysial fusion in the tibia and femur occurs at from eighteen to twenty years, it seems unwise to assume, in view of the terminal retardation in growth found

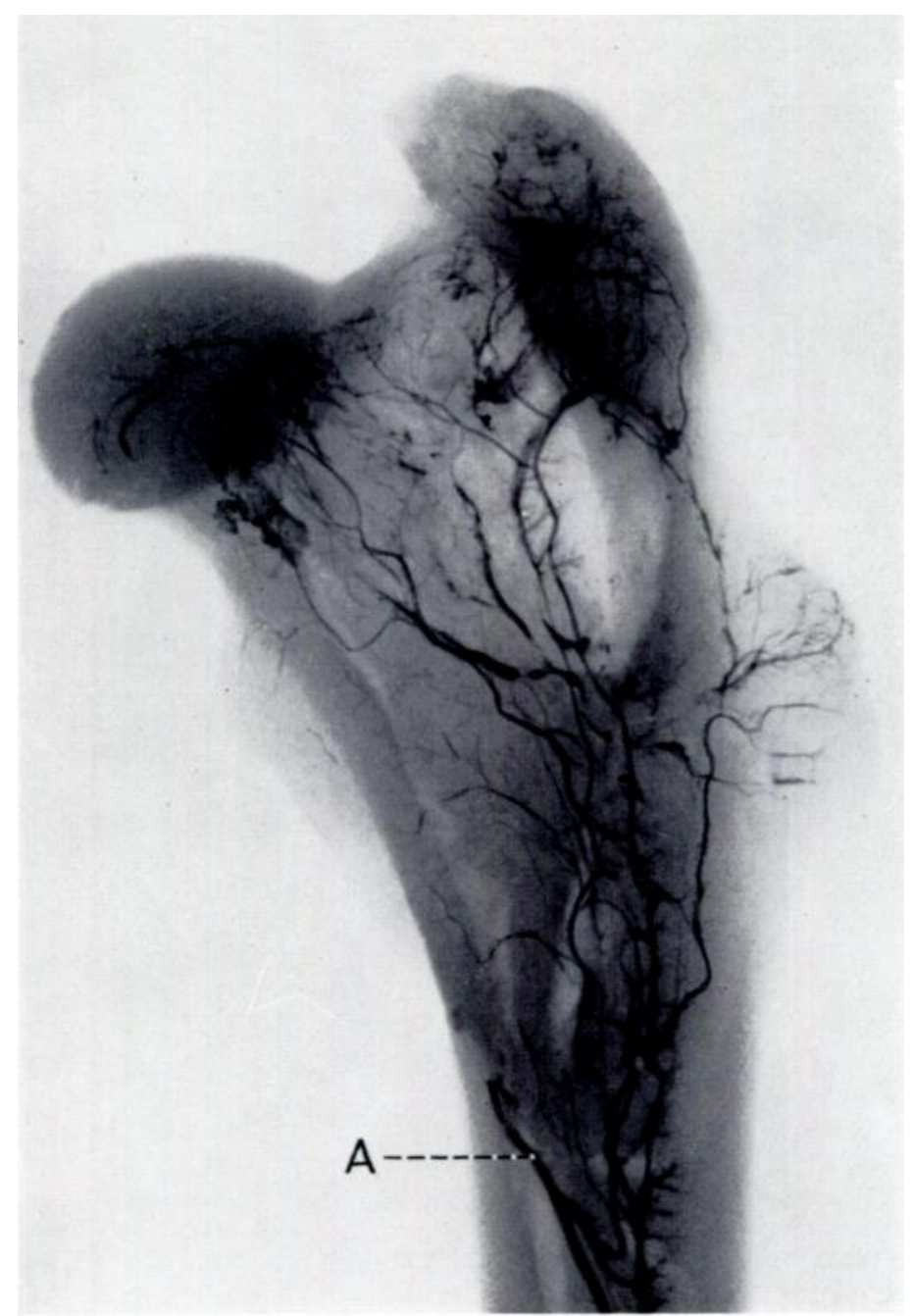

Fig. 5

Arteriograph of the upper end of a normal femur of an adult rabbit. The principal nutrient artery, $A$, divides into ascending and descending branches on entering the medulla. $(\times 4$.

experimentally, that shortening due to overriding fractures of the femur and tibia in children will be annulled at maturity. There is no clinical survey to show this.

Femora may behave differently from tibiae after a diaphysial disturbance to the medullary arterial system. Bisgard (1936) found that overriding fractures caused an initial relative diminution, subsequent lengthening and final shortening of the tibia in one goat, but a final lengthening in its twin. Trueta (1953), working on rabbit tibiae, was convinced that by prolonged 
interruption of the nutrient and periosteal circulation of the shaft he was able to increase bone growth. It is conceivable that exclusion of the tibial principal nutrient artery might cause a more prolonged increase in vascularity of the growth cartilages, because there is no artery supplying the tibia comparable with the artery of the trochanteric fossa, a large vessel which is at some distance from the superior growth cartilage of the femur.

It was first pointed out by Grégoire and Carrière (1921) that the human femur has two principal nutrients. This might allow for discrepancies in behaviour of children's femora and tibiae after fracture.

\section{SUMMARY}

1. The principal nutrient canal of the femur in day-old rabbits was occluded and subsequent femoral growth observed.

2. An initial shortening is followed by equalisation and a final absolute shortening of the order of 3 per cent in occluded femora as compared with controls.

3. It is emphasised that the medullary arterial system, fed by principal nutrient, metaphysial and epiphysial arteries, is the mechanism for the delivery of arterial blood to long bones, and that the arteries of bone extremities are of overwhelming importance in the nutrition of the long bone as a whole.

It is a pleasure to acknowledge the help and advice I have received from Professor R. G. Harrison in the preparation of this paper. My thanks are due to Mr L. G. Cooper and Mr A. Taunton for their technical assistance with the photography.

\section{REFERENCES}

Bisgard, J. D. (1931): Effect of Sympathetic Ganglionectomy Upon Bone Growth. Proceedings of the Society for Experimental Biology and Medicine, 29, 229.

Bisgard, J. D. (1933): Longitudinal Bone Growth. The Influence of Sympathetic Deinnervation. Annals of Surgery, $97,374$.

BisGARD, J. D. (1936): Longitudinal Overgrowth of Long Bones with Special Reference to Fractures. Surgery, Gynecology and Obstetrics, 62, 823.

Brookes, M., and Harrison, R. G. (1957): The Vascularization of the Rabbit Femur and Tibiofibula. Journal of Anatomy, 91, 61.

BRUNSCHWIG, A. (1930): Experimental Infarction of Bone Marrow. Proceedings of the Society for Experimental Biology and Medicine, 27, 1,049.

BurdicK, C. G., and SiRIS, I. E. (1923): Fractures of the Femur in Children. Annals of Surgery, 77, 736.

Chander, F. A. (1937): Local Overgrowth. Journal of the American Medical Association, 109, 1,411.

DAvid, V. C. (1924): Shortening and Compensatory Overgrowth Following Fractures of the Femur in Children. Archives of Surgery, 9, 438.

Drinker, C. K., Drinker, K. R., and Lund, C. C. (1922): Circulation in the Mammalian Bone Marrow. American Journal of Physiology, 62, 1.

Ferguson, A. B. (1933): Surgical Stimulation of Bone Growth by a New Procedure. Journal of the American Medical Association, 100, 26.

Grégoire, R., and Carrière, C. (1921): Circulation arterielle intraosseuse du fémur et du tibia. Comptes Rendus de l'Association des Anatomistes à Toulouse, 16, 179.

Harris, H. A. (1929): The Vascular Supply of Bone, with Special Reference to the Epiphysial Cartilage. Journal of Anatomy, 64, 3.

Harrison, R. G., and Gossman, H. H. (1955): The Fate of Radiopaque Media Injected into the Cancellous Bone of the Extremities. Journal of Bone and Joint Surgery, 37-B, 150.

Horton, B. T. (1932): Hemihypertrophy of Extremities Associated with Congenital Arteriovenous Fistula. Journal of the American Medical Association, 98, 373.

Huggins, C., and Wiege, E. (1939): The Effect on the Bone Marrow of Disruption of the Nutrient Artery and Vein. Annals of Surgery, 110, 940.

Hunter, W. (1743): Of the Structure and Diseases of Articulating Cartilages. Philosophical Transactions, London, 42, 514.

Johnson, R. W., Jun. (1927): A Physiological Study of the Blood Supply of the Diaphysis. Journal of Bone and Joint Surgery, 9, 153. 
KistLeR, G. H. (1934): Sequences of Experimental Infarction of the Femur in Rabbits. Archives of Surgery, 29, 589.

Kolodny, A. (1923): The Periosteal Blood Supply and Healing of Fractures. Journal of Bone and Joint Surgery, 5, 698.

LANGER, K. (1876): Über das Gefässsystem der Röhrenknochen, mit Beiträgen zur Kenntniss des Baues und der Entwicklung des Knochengewebes. Separatabdruck aus dem XXXVI Bande der Denkschriften der Mathematisch-Naturwissenschaftlichen Classe der Kaiserlichen Akademie der Wissenschaften. Wien: Aus der Kaiserlich-Königlichen Hof- und Staatsdruckerei.

LeXer, E. (1922): Über die Entstehung von Pseudarthrosen nach Frakturen und nach Knochentransplantationen. Archiv für klinische Chirurgie, 119, 520.

MARNEFFE, R. DE (1951): Recherches morphologiques et expérimentales sur la vascularisation osseuse. Brussels: Acta Medica Belgica.

Moore, J. E., and Corbetr, J. F. (1914): Studies on the Function of the Periosteum. Surgery, Gynecology and Obstetrics, 19, 5.

NAKahARA, T., and Dilger, A. (1909): Subkutane und intramuskuläre Knochenneubildungen durch Injektion bezw. Implantation von Periostemulsion. Beiträge zur klinischen Chirurgie, 63, 235.

Ollier, L. (1867): Traité expérimental et clinique de la régénération des os et de la production artificielle du tissu osseux. Paris: V. Masson et fils.

Testut, L. (1880): Vaisseaux et nerfs des tissus conjonctifs fibreux, séreux et osseux. Paris: Ostave Doin. Thèse d'agrégation.

Truesdell, E. D. (1921): Inequality of the Lower Extremities Following Fractures of the Shaft of the Femur in Children. Annals of Surgery, 74, 498.

TruerA, J. (1953): The Influence of the Blood Supply in Controlling Bone Growth. Bulletin of the Hospital for Joint Diseases, 14, 147.

Wilson, P. D., and Thompson, T. C. (1939): A Clinical Consideration of the Methods for Equalizing Leg Length. Annals of Surgery, 110, 992.

Wu, Y. K., and Miltner, L. J. (1937): A Procedure for Stimulation of Longitudinal Growth of Bone. An Experimental Study. Journal of Bone and Joint Surgery, 19, 909. 